\title{
Heat Transfer Analysis on a Triangular Fin
}

\author{
Sandhya Mirapalli ${ }^{1}$, Kishore.P.S ${ }^{2}$ \\ ${ }^{1}$ (M.E student, Heat Transfer studies in Energy Systems, Dept. of Mechanical Engg., Andhra University, Visakhapatnam, A.P, \\ India.) \\ 2 (Ph.D, Professor, Dept. of Mechanical Engg. Andhra University, Visakhapatnam, A.P, India.)
}

\begin{abstract}
Heat transfer by convection between a surface and the fluid surrounding can be increased by attaching to the surface called fins. The heat conducting through solids, walls, or boundaries has to be continuously dissipated to the surroundings or environment to maintain the system in a steady state condition. In many engineering applications large quantities of heat needed to be dissipated from small areas. The fins increase the effective area of a surface thereby increasing the heat transfer by convection. Rectangular fin and triangular fins are straight fins. Triangular fins are attractive, since for an equal heat transfer it requires much less volume than rectangular fin. Hence the fins have practical importance because it gives maximum heat flow per unit mass with ease of manufacture. In an air-cooled engine, rectangular and triangular fins are provided on the periphery of engine cylinder. Heat transfer analysis is carried out by placing rectangular and then triangular fins. Analysis is carried out by varying temperatures on the surface of the cylinder from $200{ }^{\circ} \mathrm{C}$ to $600^{\circ} \mathrm{C}$ and varying length from $6 \mathrm{~cm}$ to $14 \mathrm{~cm}$. Input parameters such as density, heat transfer coefficient, thermal conductivity and thickness of fin are taken and output parameters such as rate of heat flow, heat flow per unit mass, efficiency and effectiveness are determined. Comparisons are presented with rectangular fins.
\end{abstract}

Keywords: Rectangular fin, Triangular fin, Heat flow rate, Heat Transfer coefficient, Efficiency and Effectiveness.

\section{INTRODUCTION}

Heat transfer is a thermal energy which occurs in transits due to temperature difference. The modes of heat transfer are conduction, convection and radiation. Fin is a thin component or appendage attached to larger body or structure. Based upon the cross sectional area type, straight fins are of different types such as rectangular fin, triangular fin, trapezoidal fin parabolic fin or cylindrical fin. Fin performance can be measured by using the effectiveness of fin, thermal resistance and efficiency. Triangular fins have applications on cylinders of air cooled cylinders and compressors, outer space radiators and air conditioned systems in space craft. Several authors paid attention in analyzing the performance of fins. Thirumaleshwar [1] in his book provided an introduction to modes of heat transfer. He had given detailed information of extended surfaces such as boundary conditions and analysis. Arora et al.[2] in their book provided an introduction to triangular fins and they had given detailed information of triangular fins its boundary conditions and analysis. Incropera [3] in his book proposed a correlation for triangular fins. He discussed two dimensional fin analysis participating in heat transfer. Mahesh et al [4] in their book gave practical applications of triangular and rectangular fins. Kumar et al. [5] In their article provided experimental investigation to predict the performance of heated triangular fin array within a vertically oriented and air filled rectangular enclosure to analyze the effects of several influencing parameters for their wide ranges; Rayleigh number $295214 \leq$ $R a \leq 773410$, fin spacing, $25 \mathrm{~mm} \leq S \leq 100 \mathrm{~mm}$ and fin height $12.5 \mathrm{~mm} \leq L \leq 37.5 \mathrm{~mm}$ for constant heat flux boundary conditions at the heated and cooled walls of the enclosure. They developed an empirical correlation relating Nusselt number to several influencing parameters. Teerakulpisut [6] in his paper presented application of modified Bessel functions in the analysis of extended surface heat transfer and differential equations are formulated from the fundamentals of conduction and convection heat transfer. Rahim et al. [7] in their paper analysed heat transfer through a wall containing triangular fins partially embedded in its volume, Coupled heat diffusion equations governing each constituent are solved numerically using an iterative finite volume method. Numerical and the analytical results are attained in their paper. It is found that the fin-root can act simultaneously as a heat sink and heat source for the wall. The heat transfer rate through the combined system is clearly seen to be maximized at a specific fin-root length. The maximum reported heat transfer rate through the triangular rooted-finned wall is recommended to utilize the triangular rooted-fin as a heat transfer enhancer for high mechanical strength structures exposed to highly convective fluid streams. Narve et al. [8] in their paper studied heat transfer characteristics of natural convection heat flow through vertical symmetrical triangular fin arrays. They studied experimentally and results are compared with equivalent rectangular fin arrays. Average and base Nusselt numbers and Grashoff number are calculated. They observed that with increase in Grashoff number, average and base Nusselt number increases, Similarly average Nusselt number increases with spacing whereas base Nusselt number increases to maximum value.

\section{DESCRIPTION AND WORKING OF FINS}

As fins are introduced to enhance heat transfer from a base which is at high temperature, rectangular fins and triangular fins are considered for analysis on two stroke air cooled engine. Engine life and effectiveness can be improved with effective cooling. The cooling mechanism of the air cooled engine is mostly dependent on the fin size. The heat is conducted through the engine parts and convected to air through the surfaces of the fins. Insufficient removal of heat from engine will lead to high thermal stresses and lower engine efficiency. As air-cooled engine builds heat, the cooling fins allow the wind and air to move the heat away from the engine. 
Considering an air cooled petrol engine with two stroke, at no load condition engine does not generate power. When load increases on an engine, the upward movement of a piston causes compression of the previously available charge inside the cylinder. Thus, during upward stroke, suction and compression of charge takes place simultaneously, and both transfer port and exhaust port remain closed. At the end of compression stroke, the charge is ignited by a high voltage electric spark. After ignition of charge, hot high pressure gases expand. The piston goes downwards and compresses the charge drawn in the crank case. At the end of expansion stroke, exhaust port which is slightly placed higher than the transfer port, opens releasing the burnt gases from cylinder to the atmosphere. Fins are provided on a periphery of engine. Exhaust heat is exposed to outside of engine cylinder. Air cooled engines have fins to radiate heat to surrounding air. Cylinder is made of cast iron and fins are made of stainless steel.

Fig. 1 and Fig. 2 below gives a layout of an air cooled cylinder provided with rectangular and triangular fins.

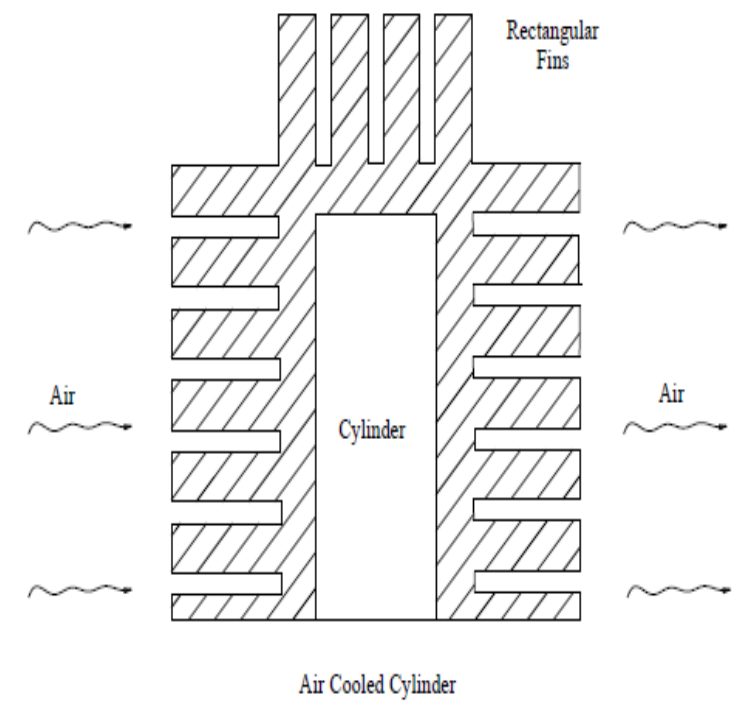

Fig.1 Air cooled cylinder with rectangular fins

Fig.1 shows rectangular fins placed around the cylinder. These fins are made of stainless steel of thickness $2.5 \mathrm{~cm}$. Fig. 2 shows a single cylinder fitted with triangular fins of thickness $2.5 \mathrm{~cm}$. As the heat developed inside a two stroke engine cylinder is more, the heat has to be dissipated to surroundings by fins. These fins fitted are having an appropriate surface area to take away the heat to surroundings.

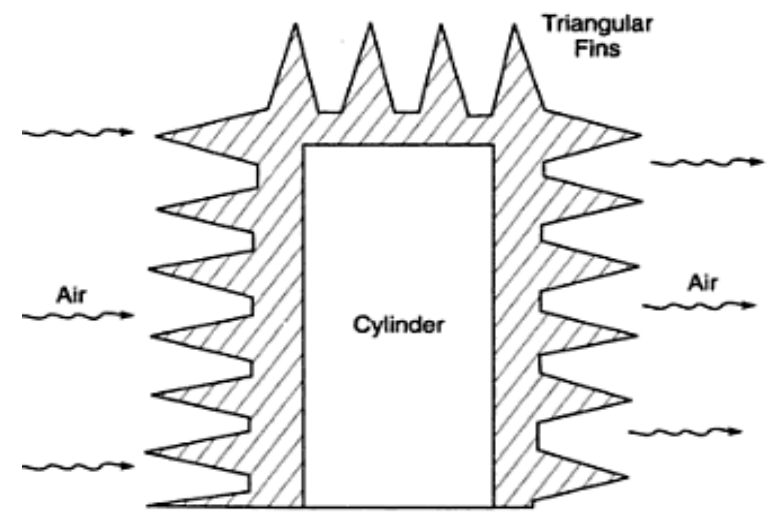

Fig.2 Air cooled cylinder with triangular fins

\section{ANALYSIS OF RECTANGULAR AND TRIANGULAR FIN}

Rectangular Fin:

The rectangular fin as shown in Fig. 3 with $\mathrm{L}$ as the length of the fin, $2 \delta$ as thickness of the fin and $\mathrm{W}$ width of fin and assuming the heat flow is unidirectional and it is along length and the heat transfer coefficient (h) on the surface of the fin is constant.

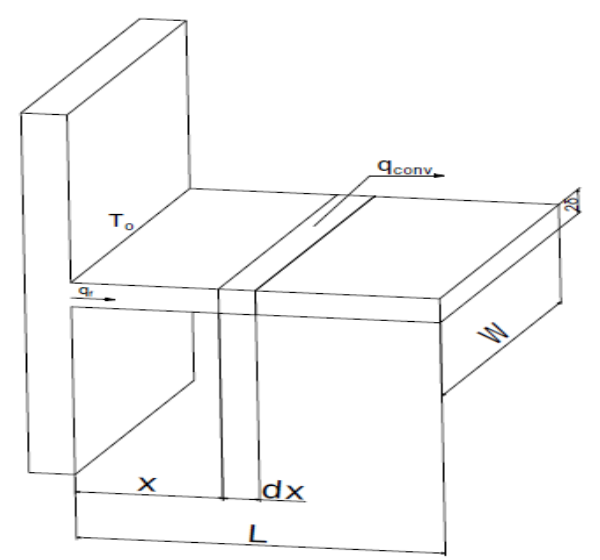

Fig.3 Rectangular fin attached to cylinder

Heat lost by fin, $\left(Q_{r}\right)$

$K A_{c} m \theta_{0} \frac{h \cos h m L+k m \sin h m L}{k m \cos h m L+h \sin h m L}$

where,

$\mathrm{k}=$ thermal conductivity, $\mathrm{W} / \mathrm{mK}$

$\mathrm{A}_{\mathrm{c}}=$ cross section area of fin, $\mathrm{m}^{2}$

$\mathrm{m}=$ fin parameter, $\left(\sqrt{h P / k A_{c}}\right)$

$\mathrm{P}=$ perimeter of fin, $(2 \mathrm{~W}+4 \delta), \mathrm{m}$

$\theta_{0}=$ temperature difference, $\mathrm{K}$

$\mathrm{h}=$ heat transfer coefficient, $\mathrm{W} / \mathrm{m}^{2} \mathrm{~K}$

Mass of rectangular fin, $\left(\mathrm{m}_{\mathrm{r}}\right)=2 \delta \times \rho \times L$

where, 
$\rho=$ density of fin material, $\mathrm{kg} / \mathrm{m}^{3}$

Rate of heat flow per unit mass through rectangular fin,

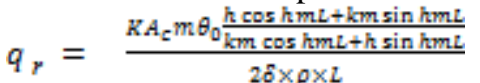

Efficiency of rectangular fin, $\left(\eta_{r}\right)$

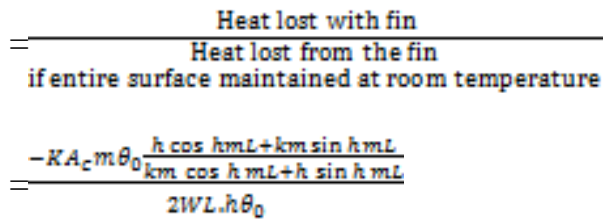

Effectiveness of rectangular fin, $\left(E_{\gamma}\right)=\frac{\text { Heat lost with fin }}{\text { Heat loss without fin }}$

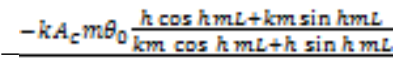

$$
\text { in } A_{c} \theta_{0}
$$

Triangular Fin:

For a triangular fin representing length of fin L, thickness, $2 \delta$ and width of fin, $\mathrm{W}$ and assuming the heat flow is unidirectional and it is along length and the heat transfer coefficient (h) on the surface of the fin is constant.

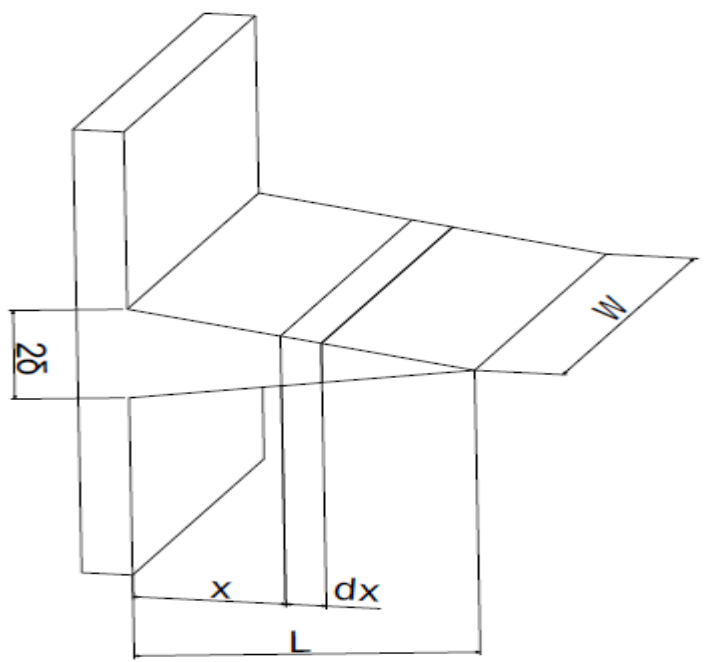

Fig.4 Triangular fin attached to cylinder

Heat lost by triangular fin,

$Q=2 W \theta_{0} \sqrt{(h k \delta)}\left[\frac{I_{1}(2 B \sqrt{L)}}{I_{0}(2 B \sqrt{L)}}\right]$

where,

$\theta_{0}=$ temperature difference, $\mathrm{K}$

$\mathrm{k}=$ thermal conductivity, $\mathrm{W} / \mathrm{mK}$

$\mathrm{B}=$ fin parameter, $(\sqrt{h L / k \delta})$
$I_{1}=$ Bessel function of first kind

$\mathrm{I}_{0}=$ Bessel function of first kind

The mass of triangular fin,

$\left(m_{t}\right)=\frac{1}{2} \times 2 \delta \times L \times W \times \rho$

$\rho=$ Density of fluid $\mathrm{kg} / \mathrm{m}^{3}$

Rate of heat flow per unit mass $(\mathrm{q})=\frac{\text { Heat flow through fin }}{\text { mass of fin }}$

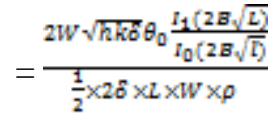

Efficiency of triangular fin $\left(\eta_{t}\right)$

$=\frac{2 W \sqrt{h k B} \theta_{0} \frac{I_{1}\left(2 B_{\sqrt{L}}\right)}{T_{0}\left(2 B_{\sqrt{2}}\right)}}{2 W L h \theta_{0}}$

Effectiveness of triangular fin, $\left(E_{t}\right)=\frac{\text { Heat lost with fin }}{\text { Heat loss without fin }}$

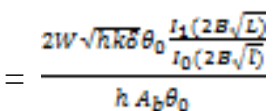

where,

$\mathrm{A}_{\mathrm{b}}=$ base area of triangular fin, $(\mathrm{W} \times 2 \delta), \mathrm{m}^{2}$

\section{RESULTS AND DISCUSSION}

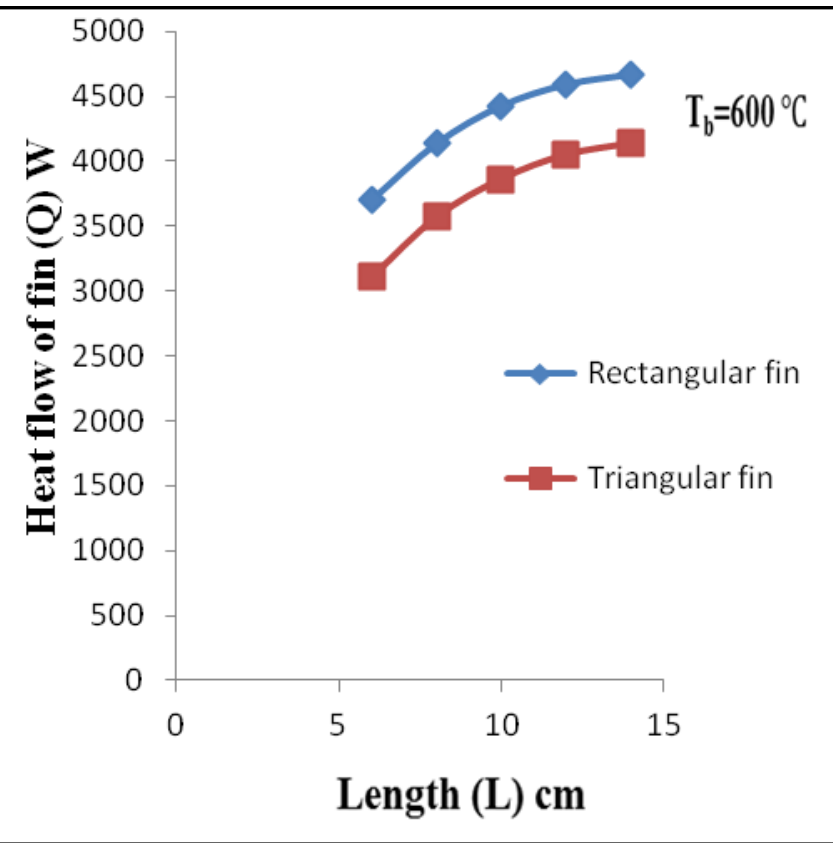

Fig.5 Variation of heat flow of the fin (Q) with length (L)

Fig. 5 shows the variation of heat flow through fin to length of the fin. It is noted that as a length is increased, heat flow increases. The increase of the two fins varies as the same 
curve, however at any point of length rectangular fins gives more heat transfer rate compared to triangular fin.

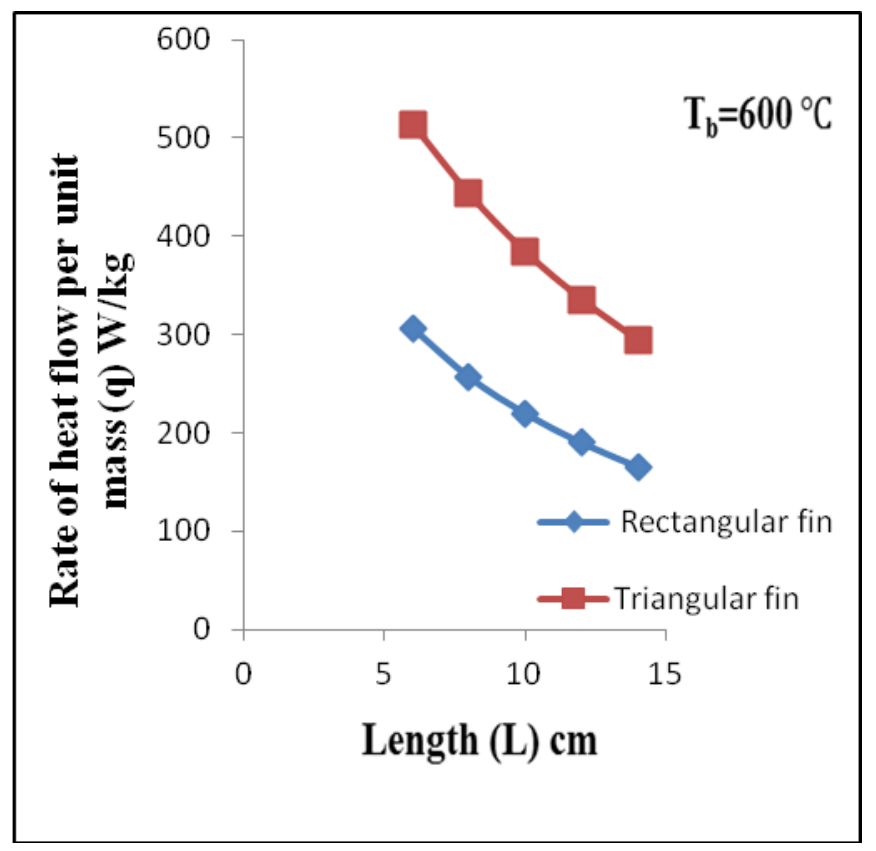

Fig.6 Variation of rate of heat flow per unit mass of fin (q) with length $(\mathrm{L})$

Fig. 6 shows a variation between rate of heat flow per unit mass to the length of fin. It is observed that the heat flow of a triangular fin is more when compared to rectangular fin at any point of length hence it is utilising most of the material for disiipation of heat.

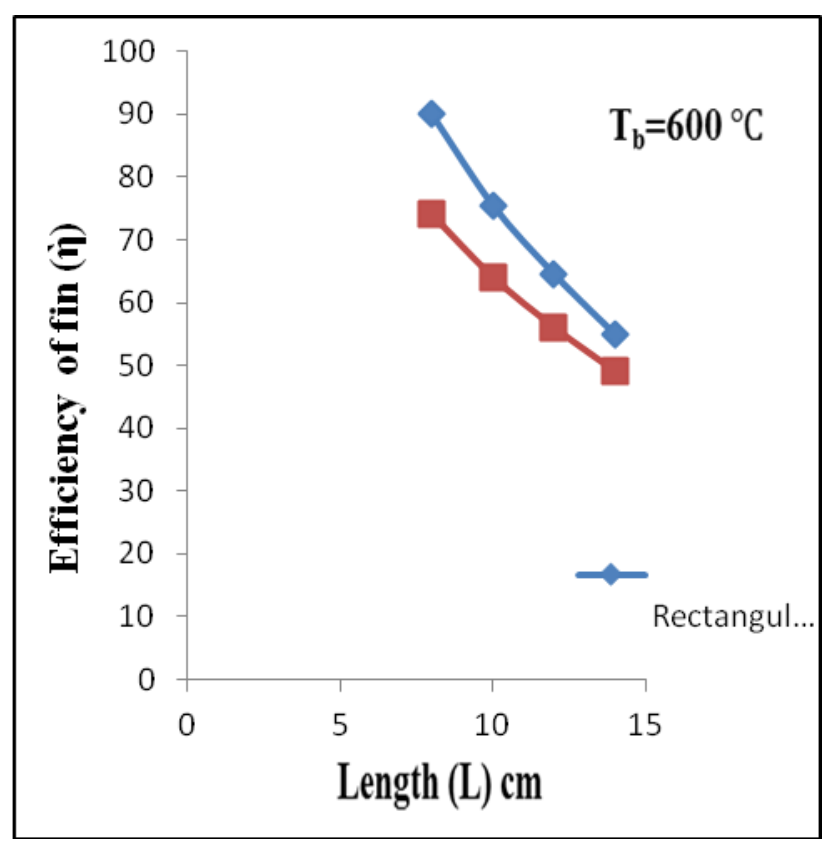

Fig.7 Variation of efficiency $(\eta)$ with length (L)

Fig. 7 shows the variation of efficiencies of fins. Efficiencies of fins are for more for shorter length compared to long length of fins. However it is understood that rectangular fins exhibits more efficiency than triangular fins.

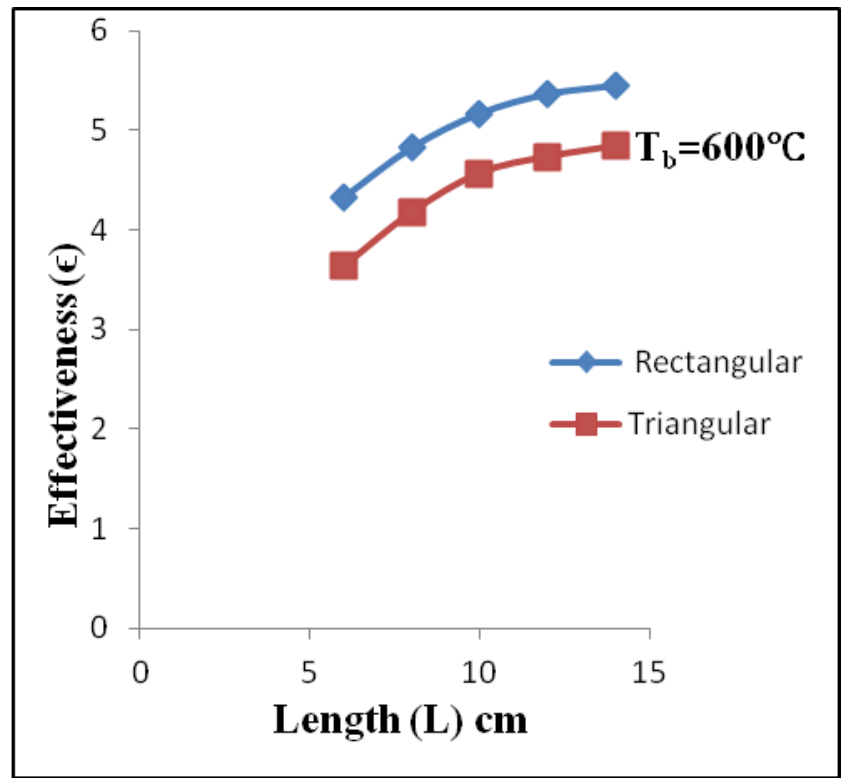

Fig.8 Variation of effectiveness $(\varepsilon)$ with length (L)

The graph Fig. 8 shows variation of effectiveness of a fin. The effectiveness of a fin increases with increase in length of a fin. In general rectangular fins, give more effectiveness than triangular fins.

Fig.9 shows variation of heat flow of fin when length is fixed at $10 \mathrm{~cm}$. It is observed that there is a steep increase of heat flow of fin. Heat flow of rectangular fin is more than triangular fin.

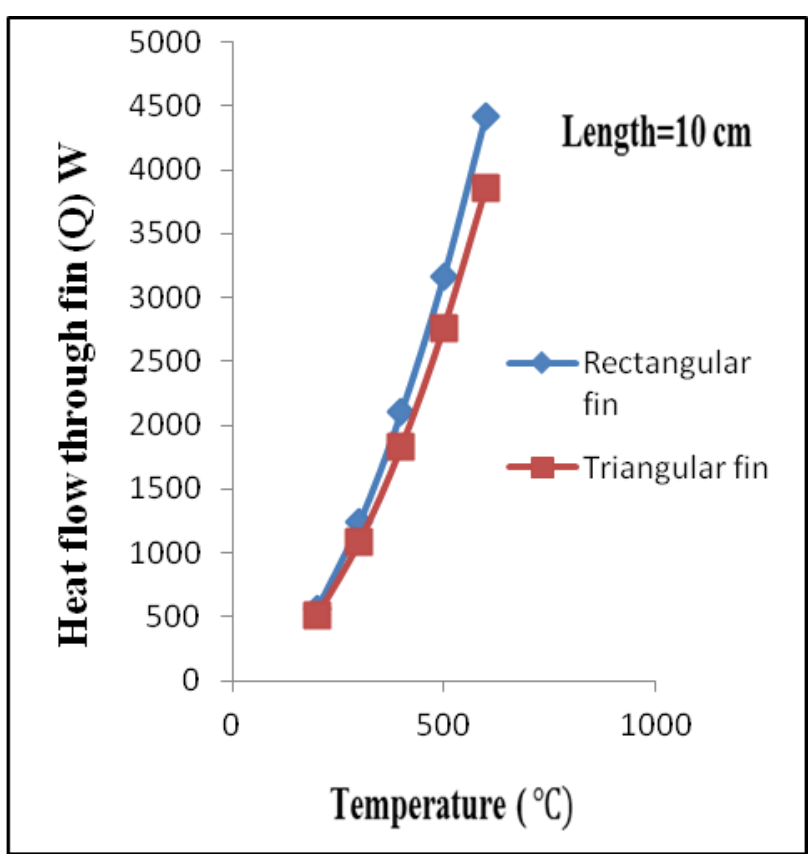

Fig.9 Variation of heat flow $(\mathrm{Q})$ with temperature $\left({ }^{\circ} \mathrm{C}\right)$ 


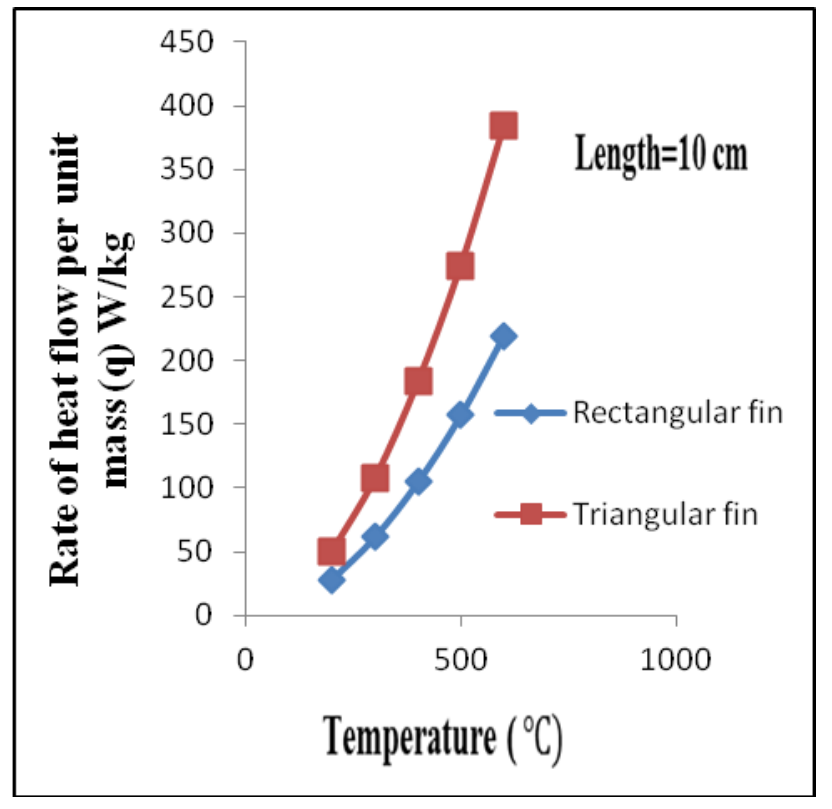

Fig.10 Variation of rate of heat flow per unit mass of fin (q) with temperature $\left({ }^{\circ} \mathrm{C}\right)$

The above diagram Fig.10 shows variation of heat flow per unit mass with respect to the increase in base temperature. For a fixed length of a fin it is seen that there is a large variation heat dissipation per unit mass from the base when compared to rectangular fin. Hence triangular fins are preferred for better heat dissipation per unit mass.

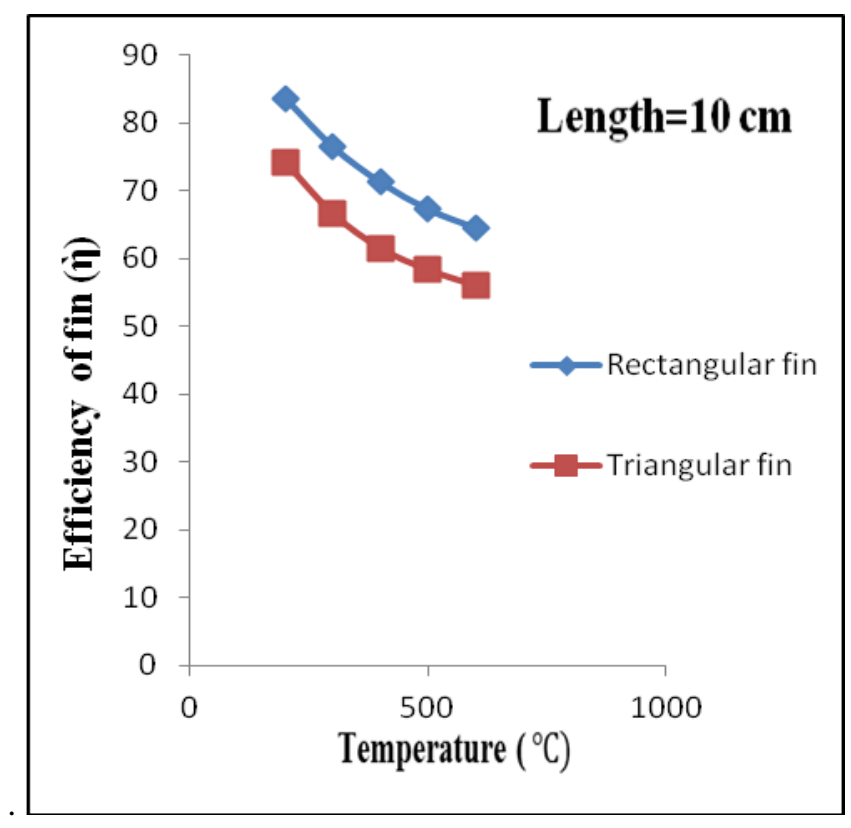

Fig.11 Variation of efficiency $(\eta)$ with temperature $\left({ }^{\circ} \mathrm{C}\right)$

Here shows Fig.11 for variation of efficiency $(\eta)$ with base temperature variation at a fixed length. There is a gradual decrease in efficiency $(\eta)$ as base temperature increases.

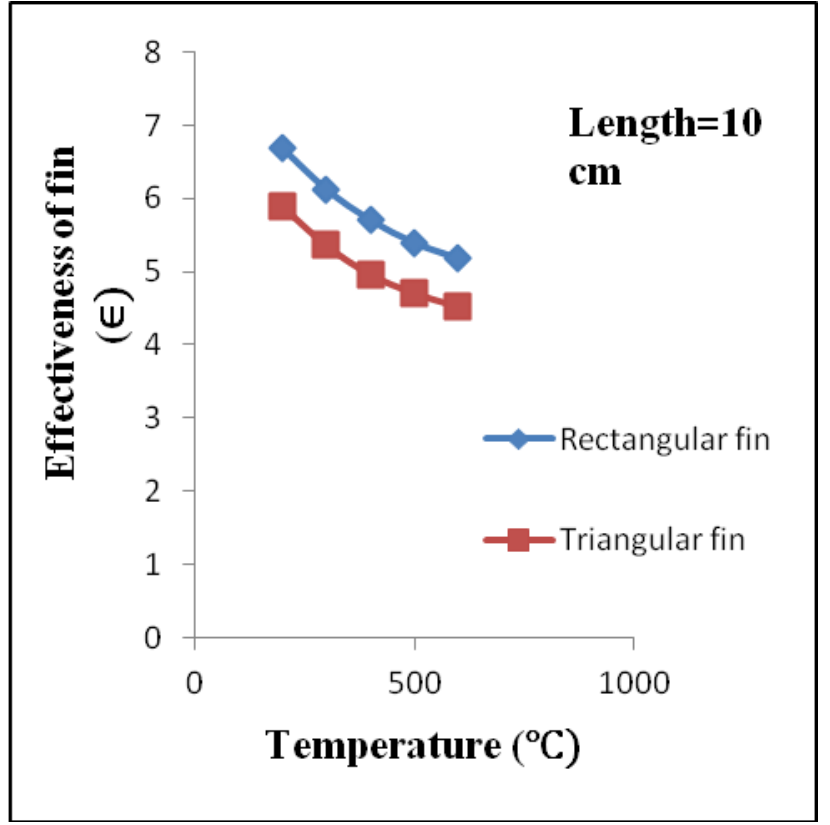

Fig.12 Variation of effectiveness $(E)$ with temperature $\left({ }^{\circ} \mathrm{C}\right)$

Fig.12 shows the variation of effectiveness with respect to base temperature. It was made clear that the effectiveness of rectangular and triangular decreases when base temperature increases and rectangular fin exhibits more effectiveness.

\section{CONCLUSIONS}

The following conclusions are arrived when the air cooled petrol engine is fitted with rectangular and triangular fins.

1. Varying the length of fin from $6 \mathrm{~cm}$ to $14 \mathrm{~cm}$ and maintaining base temperature at $600^{\circ} \mathrm{C}$,

a) Heat flow from triangular fin is increased by $33.14 \%$ compared to rectangular fin of $25.97 \%$,

b) Rate of heat flow per unit mass of rectangular fin is decreased by $46 \%$ compared to triangular fin of $42.9 \%$,

c) Efficiency of triangular fin is decreased by $41.89 \%$ compared to rectangular fin of $45.8 \%$,

d) Effectiveness of triangular fin is increased by $33.14 \%$ compared to rectangular fin of $25.8 \%$.

2. Varying base temperature of fin from $200^{\circ} \mathrm{C}$ to $600^{\circ} \mathrm{C}$ keeping the length fixed at $10 \mathrm{~cm}$.

a) Heat flow of triangular fin is increased by $87.9 \%$ compared to rectangular fin of $87.14 \%$.

b) Rate of heat flow per unit mass of triangular fin is increased by $86.78 \%$ compared to rectangular fin of $87.14 \%$.

c) Efficiency of triangular fin is decreased by $24.52 \%$ compared to rectangular fin of $22.72 \%$.

d) Effectiveness of triangular fin is decreased by $23.45 \%$ compared to rectangular fin of $22.6 \%$. 
3. From the above, it can be concluded that triangular fins are preferred when maximum material of fin is to be utilised for best heat dissipation.

\section{REFERENCES}

[1] M. Thirumaleshwar, Fundamentals of Heat and Mass Transfer, Dorling Kindersely, 2011.

[2] S.C.Arora, S.Domkundwar and Anand V.Domlundwar, A Course in Heat and Mass Transfer, Dhanapati Rai and Co. (P) Ltd, 2004.

[3] F.P.Incropera, Fundamentals of Heat and Mass Transfer, John Wiley and Sons.

[4] Mahesh, M. Rathore, Raul Raymond Kapuno, Engineering Heat Transfer, Jones and Bartlett Learning, 2011.

[5] Gaurav Kumar, Kamal Raj Sharma, Ankur Dwivedi, Alwar Singh Yadav and Hariram Patel, Experimental Investigation of Natural Convection from Heated Triangular Fin Array within a Rectangular Array, Research India Publications, Vol. 4, pp.203-210, 2014.

[6] Dr. Somunk Teerakulpisut, Application of Modified Bessel functions in Extended Surface Heat Transfer, Vol. 22, pp.61-74, 1995.

[7] Abdul Rahim, A.Khaled and A.Abdullatif, Heat Transfer Enhancement via Combined Wall and Triangular- Rooted Fin System, KSA Journal of Electronics Cooling and Thermal Control, Vol. 4, pp.12-21, 2014.

[8] N.G.Narve, N.K.Sane, R.T.Jadhav, Natural Convection Heat Transfer from Symmetrical Triangular Fin Arrays on Vertical Surface, International Journal of Scientific and Engineering Research, Vol.4, May, 2013. 